Running head: EMOTION AND ESCALTION

Journal of Applied Psychology, in press

Understanding the Emotional Aspects of Escalation of Commitment:

The Role of Negative Affect

Kin Fai Ellick Wong \& Michelle Yik

Hong Kong University of Science and Technology

Jessica Y. Y. Kwong

The Chinese University of Hong Kong

\begin{abstract}
Author's Notes
Kin Fai Ellick Wong, Department of Management of Organizations, Hong Kong University of Science and Technology; Michelle Yik, Division of Social Science, Hong Kong University of Science and Technology; Jessica Y. Y. Kwong, Department of Marketing, the Chinese University of Hong Kong.

Preparation of this article was supported by RGC Direct Allocation Grants (DAG02/03.HSS14 and DAG03/04.HSS14) awarded to Michelle Yik and an RGC Direct Allocation Grant (DAG02/03.BM53) awarded to Kin Fai Ellick Wong.

We thank Irene Lee and Benjamin Miu for their help in conducting the experiment in Study 3. Correspondence can be directed to Ellick Wong, Department of Management of Organizations, School of Business and Management, Hong Kong University of Science \& Technology, Clear Water Bay, Kowloon, HONG KONG. Electronic mail: mnewong@ust.hk
\end{abstract}




\begin{abstract}
Despite the importance of understanding the emotional aspects of organizational decision-making, prior research has paid scant attention to the role of emotion in escalation of commitment. This paper attempts to fill this gap by examining the relationship between negative affect and escalation of commitment. Results showed that regardless of whether negative affect was measured as a dispositional trait (Neuroticism) in Studies 1 and 2 or as a transient mood state in Study 3, it was negatively correlated with escalation tendency when one was personally responsible for a prior decision. This pattern of results is consistent with the predictions derived from the coping perspective, suggesting that people seek to escape from the unpleasant emotions that are associated with escalation situations.
\end{abstract}




\section{Understanding the Emotional Aspects of Escalation of Commitment: The Role of Negative Affect}

Research on organizational decision-making has demonstrated that individuals exhibit strong tendencies to be locked into losing courses of action (see Brockner, 1992; Staw, 1997, for reviews). Over the past three decades, a large body of research studying the psychology of this so-called “escalation of commitment” phenomenon has focused primarily on its cognitive determinants, including self-justification (Staw, 1976, 1981; Staw, Barsade, \& Koput, 1995), problem framing (Whyte, 1986, 1993), sunk costs (Arke \& Blumer, 1985), goal substitution (Conlon \& Garland, 1993; Moon, 2001a), self-efficacy (Whyte, Saks, \& Hooks, 1997), accountability (Kirby \& Davis, 1998), and illusion of control (Staw, 1997). Altogether, a substantial body of research now offers insights into the cognition of why decision makers "throw good money after bad."

Yet, some scholars (Bazerman Tenbrunsel, \& Wade-Benzoni, 1998; Walsh, 1995) remain dissatisfied with previous work on organizational decision making, which they have characterized as inadequate and incomplete. For the most part, they suggest that researchers have focused mostly on the cognitive aspects of decision-making but have not adequately examined the issue through an emotional perspective (Fineman, 2000). Walsh (1995) explicitly stated, "If our work is to have strong external validity, we must consider the emotional basis of work and its relationship to the cognitive question we have been asking” (p. 307). Along a similar vein, Bazerman et al. (1998) and Fineman (2000) argued that emotion is essentially embodied in decision-making processes, a notion that is supported by a growing body of research (Arkes, Kung, \& Hutzel, 2002; Isen, 2000; Luce, Bettman, \& Payne, 1997; Mellers, 2000; Staw \& Barsade, 1993; Tykocinski \& Pittman, 1998;

Zeelenberg \& Beattie, 1997). These scholars have suggested that the examination of emotion is much needed to advance our understanding of escalation of commitment.

This article is an initial step towards a systematic investigation of the role of emotion in 
escalation of commitment. The three studies reported here were designed to examine individuals' escalation tendencies as a function of negative affect. This was done by testing the relationship between trait affect (i.e., Neuroticism, enduring individual differences in sensitivity to negative affect) and escalation of commitment (Studies 1 and 2) and the relationship between state affect and escalation of commitment (Study 3).

Previous research has found limited evidence of individual differences in escalation of commitment (Levi, 1981, cited in Whyte et al., 1997; Staw \& Ross, 1978). If our hypotheses pertaining to the effects of personality traits (i.e., Neuroticism) are supported by data, our work will actually extend the literature in a new direction. That is, in addition to revealing the role of negative emotion in escalation of commitment, this research helps delineate the situations under which individual differences have the greatest impact on escalation of commitment.

We first begin with a discussion of the key features of both escalation of commitment and negative affect in organizational research. We then consider the theoretical linkages between these two observed behaviors. This analysis reveals that not only is negative affect an important predictor of escalation of commitment, but it also may moderate the personal responsibility effects on escalation of commitment. For instance, one of the perspectives to be discussed below predicts that people who are low in negative affect tend to escalate more when they are held responsible for a prior decision than when they are not. This pattern of relations would be weakened among those who are high in negative affect. This potential moderating effect appears to have important theoretical and practical implications because personal responsibility has long been regarded as one of the most robust determinants of escalation of commitment (Arkes \& Blume, 1985; Brockner, 1992; Staw, 1976).

\section{Escalation of Commitment}

Decision makers in organizations often face the dilemma of whether to withdraw from a failing 
course of action (e.g., when a prior decision receives negative feedback) or to invest more resources to turn the current losses around. This situation has been coined an "escalation situation" and is characterized as "predicaments where costs are suffered in a course of action, where there is an opportunity to withdraw or persist, and where the consequences of persistence and withdrawal are uncertain” (Staw \& Ross, 1987, p. 40). The defining features of a typical escalation situation are as follows (Brockner, 1992; Staw \& Ross, 1987). First, a large amount of resources, such as money, time, or effort, has already been invested in a certain course of action (i.e., sunk costs). Second, this course of action receives negative feedback. Finally, this situation allows the decision maker either to continue the investment in an attempt to recover the sunk costs or to withdraw entirely from the course of action. Escalation of commitment is typically manifested as the tendency to continue to invest in the losing course of action (Brockner, 1992; Staw, 1976, 1997; Staw \& Ross, 1987), particularly when one is personally responsible for the initiation of the failing investment (Arke \& Blumer, 1985; Conlon \& Park, 1987; Staw, 1976). Researchers often regard personally non-responsible conditions as control conditions. Factors that are theoretically related to escalation of commitment are found to be stronger under the personally responsible conditions than under personally non-responsible conditions (e.g., Schaubroeck \& Williams, 1993).

Escalation of commitment is not restricted to investment contexts. Research has found that it also occurs in selection-appraisal situations (Bazerman, Beekun, \& Schoorman, 1982; Schoorman, 1988). It has been shown that a poorly performing employee was evaluated more favorably when the appraisal was completed by the person responsible for hiring the employee than when it was done by another person (Schoorman, 1988). That is, escalation of commitment to the prior hiring decision is manifested in terms of the elevated evaluation scores of the employee in the appraisal context.

$\underline{\text { Negative Affect in Organizational Research }}$ 
Two approaches have been pursued to study negative affect in organizational research. First, negative affect is conceptualized as a dispositional trait such as the Big Five's Neuroticism (e.g., Brief \& Weiss, 2002; Costa \& McCrae, 1992) or Negative Affectivity (Watson \& Clack, 1984) ${ }^{1}$. This dispositional approach considers "consistent, long-term individual differences in affective experience - that is, what traditionally has been called trait affect” (Watson, 2000, p. 15). The superfactor of Neuroticism has long been argued to be a temperamental trait that influences feelings and behaviors (H. J. Eysenck, 1992; H. J. Eysenck \& M. W. Eysenck, 1985; Tellegen, 1985) and yields robust relations to mood states (Costa \& McCrae, 1980, 1984, 1996; Diener \& Emmons, 1984; Izard, Libero, Putnam, \& Haynes, 1993; Meyer \& Shack, 1989; Yik \& Russell, 2004; Yik et al., 2002). The robustness of the findings on Neuroticism led Tellegen (1985; Watson \& Clark, 1984) to argue that Neuroticism should be renamed as "Negative Emotionality”.

Neuroticism is characterized by sensitivity to negative events resulting in the experiences of unpleasant emotions such as anxiety, depression, hostility, and self-consciousness (Costa \& McCrae, 1992). A large body of research has demonstrated that Neuroticism and its related constructs (e.g., Watson \& Tellegen’s [1985] Negative Affect) are closely related to a wide variety of dependent variables in the organizational context (e.g., Lam, Yik, \& Schaubroeck, 2002; Tokar, Fischer, \& Subich, 1998), including job satisfaction (Judge, Heller, \& Mount, 2002), performance motivation (Judge \& Ilies, 2002), leadership (Judge, Bono, Ilies, \& Gerhardt, 2002), and job stress perception (Brief et al., 1988; Schaubroeck, Judge, \& Taylor, 1998).

By definition, a negative outcome should induce stronger negative affect among those with high Neuroticism than among those with low Neuroticism (Brief, Butcher, \& Roberson, 1995; Costa \& McCrae, 1992; Watson 2000). This difference naturally enables researchers to examine the general impacts of negative affect on escalation of commitment by observing escalation tendencies of people with different levels of Neuroticism (see Staw \& Barsade, 1993 for a similar argument on 
understanding the role of emotion by studying effects of dispositional variables). To test the influence of the disposition of negative affect on escalation of commitment in paper-and-pencil scenarios, we used the trait measure of negative affect, namely Neuroticism, in Studies 1 and 2.

The second approach to study negative affect in organizational research is to conceptualize it as a momentary state where affective feeling for an instant moment of time was measured (Bohle \& Tilley, 1993; Portello \& Long, 2001; Weiss, Nicholas, \& Daus, 1999; Wofford, Goodwin, \& Daly, 1999; Weiss \& Kurek, 2003 for a review). This momentary state represents “short-term, transient feelings, which traditionally have been called state mood or state affect in the psychological literature” (Watson, 2000, p. 15). This approach is particularly useful in capturing the instant emotional reactions of a specific time in which affective experience is occurring. Such a state affect has behavioral consequences that are of great relevance to organizational functioning (Weiss, 2002). Past research findings indicate the consequences of the state affect on work performance (e.g, Sarason, Pierce, \& Sarason, 1996; Martin \& Tesser, 1996). To examine instant psychological effects of affective experience on escalation of commitment, we used the state measure of negative affect in Study 3.

\section{$\underline{\text { Theory and Hypotheses }}$}

In this section, we outline the potential Negative Affect-Responsibility interaction patterns from three different perspectives, namely, coping, depressive realism, and cognitive dissonance. These three perspectives are chosen because, as revealed below, each delineates a distinct patter of conceptual overlap between negative affect and escalation of commitment. These three perspectives lead to competing hypotheses, each suggesting a unique Negative Affect-Responsibility interaction pattern. In this research, our intention is to provide a common level field on which to test these competing hypotheses. 


\section{$\underline{\text { Coping }}$}

The literature on coping focuses on the strategies (or styles) individuals use to reduce stress and anxiety induced by unpleasant and stressful situations (Endler \& Parker, 1990; Miller, Brody, \& Summerton, 1988). The converging evidence is that the likelihood of using the avoidance-withdrawal strategy increases as the strength of a person's negative affect increases (Endler \& Parker, 1990; O’Brien \& DeLongis, 1996; Terry, 1994). For example, under negative situations, people with high neuroticism experience a relatively high level of stress that is difficult to tolerate. Accordingly, they tend to "avoid a particular stressful situation ... by engaging in another task rather than the task at hand” (Endler \& Parker, 1990, p. 846). People with low neuroticism, on the other hand, are less likely to rely on the avoidance-withdrawal strategy, presumably because they experience a relatively low level of stress such that avoidance is deemed unnecessary. Therefore, a person is more likely to withdraw from the current negative situation when he/she is more likely to experience a negative affect (e.g., those who have high Neuroticism) or when he/she is in a situation that is more likely to elicit a negative affect.

The reliance on the avoidance-withdrawal strategy to cope with negative situations is relevant to making decisions under escalation situations in two ways. First, escalation situations are likely to be perceived as negative situations that induce experiences of unpleasant emotions such as stress and anxiety. More precisely, one of the defining features of escalation situations is that the individual's prior decision receives negative feedback (Brockner, 1992; Staw, 1997). The negative feedback signals the possibility that the prior decision might have been incorrect and hence would pose a challenge to one's positive self-image, resulting in a negative affect (Baumeister, 1993; Baumeister, Smart, \& Boden, 1996). Thus, such a situation probably induces a negative affect, which influences subsequent decisions.

Second, escalation situations provide a context for individuals to execute different coping 
strategies to reduce stress and anxiety. Specifically, under escalation situations, decision makers have the choice either to withdraw entirely from the current situation and switch to another course of action or be persistent with the current course of action to see if the negative situation will be turned around (Brockner, 1992; Staw, 1997). Thus, such a situation allows individuals to choose to withdraw from the current escalation situation as the means to avoid negative affect.

From the coping perspective, a strong negative affect would lead one to be more uncomfortable, and hence would likely withdraw from the negative situation in order to reduce the experience of negative affect. In an escalation situation, choosing to withdraw entirely from the current course of action corresponds to the avoidance-withdrawal coping strategy because by withdrawal one can avoid receiving further negative feedback from the same source and hence avoid experiencing a negative affect. Thus, from the coping perspective, a high level of negative affect pushes individuals away from the current situation to reduce the unpleasant feelings experienced; that is, they reduce the negative affect through withdrawal. Thus, the coping perspective naturally leads to a negative Negative Affect-Escalation relationship.

This negative relationship, however, is expected to be less pronounced when one is not responsible for the prior decision. Specifically, when a prior decision is initiated by another person, any negative feedback on that decision is not attributable to the current decision maker and this does not challenge the current decision maker. In this situation, people experience only a relatively low level of negative affect. In addition, although people may have varied degrees of negative affect under such conditions, the source of the negative affect is not from the escalation situation because it is not self-relevant. This means that avoiding the same situation in a subsequent situation may not be very useful to reducing the negative affect. Thus, from the coping perspective, a negative affect will have only weak effects, if any, on escalation of commitment under personally non-responsible conditions. In sum, on the basis of the coping perspective, we posit the following hypothesis (see 
Figure 1, left panel):

Hypothesis 1: There is a Negative Affect $\times$ Responsible interaction effect on Escalation of

Commitment. When one is personally responsible for a failing decision, there is a negative correlation between negative affect and escalation. When one is not personally responsible for a failing decision, this negative correlation is significantly reduced.

Insert Figure 1 about here

\section{Depressive Realism}

Alloy and Abramson (1979) and others (Lewinsohn, Mischel, Chaplin, \& Barton, 1980; Taylor \& Brown, 1988; but see Dunning \& Story, 1991; Shrauger, Mariano, \& Walter, 1998 for the other view) have proposed a “depressive realism” perspective, which posits that depressed people are less biased information processors than those who are not depressed. The depressed exhibit a remarkable degree of realism in judgments about their personal and social worlds, whereas the less depressed tend to exhibit unrealistic optimism about their own ability to attain a desirable future outcome (e.g.,. Heine \& Lehman, 1999; Weinstein, 1980). Depressed individuals tend to (a) fail to exhibit self-serving bias (Kuiper, 1978), (b) have more accurate evaluations of the self and others (Brown, 1986), and (c) give more appropriate weight to statistical information in predictions on the self and others (Alloy \& Abrens, 1987). In sum, the depressive realism perspective points to a “sadder-but-wiser” effect (Alloy \& Abramson, 1979; Staw \& Barsade, 1993).

The depressive realism perspective naturally leads to the prediction that individuals with high levels of negative affect are less likely to be subjected to decision biases than are individuals with low levels of negative affect because the former are "wiser" (i.e., more realistic and less optimistic). The escalation literature has recognized that throwing good money after bad is not wise (Bazerman, 
1994; Staw, 1981, 1997). It has been shown that people who take sunk costs into account when making decisions under escalation situations violate the rationality definition of normative theory (Arkes \& Blumer, 1985; Staw, 1976). Indeed, there has been a great deal of effort devoted to developing debiasing techniques in escalation of commitment (Brockner, Shaw, \& Rubin, 1979; Nathanson et al., 1982; Simonson \& Staw, 1992; Staw \& Ross, 1987). Thus, the depressive realism perspective predicts a negative relationship between negative affect and escalation because negative affect leads people to be more likely to make a more realistic decision by escalating less.

Furthermore, this perspective predicts that this negative relationship will still be held in conditions in which one is not responsible for the prior decision. Specifically, what underlies the "sadder-but-wiser" effect is the relatively realistic view of "sadder" individuals, which should be independent of personal involvement in a prior decision. That is, individuals with stronger negative affect (i.e., sadder) generally tend to avoid overestimating their control over the occurrence of events, whereas those with weaker negative affects tend to have unrealistically optimistic views on their control to achieve desirable outcomes (Alloy \& Abramson, 1979). Thus, irrespective of who made the prior decision, sadder individuals should be more pessimistic/realistic than less sad individuals in achieving desirable outcomes from the decision. In sum, on the basis of the depressive realism perspective, we posit the following hypothesis (See Figure 1, middle panel):

Hypothesis 2: There is a negative correlation between Negative Affect and Escalation of

Commitment, regardless of who is responsible for the prior decision.

\section{Cognitive Dissonance}

One of the most dominant explanations for escalation of commitment is the self-justification explanation (Brockner, 1992; Staw, 1976, 1981). This explanation stems from Festinger’s (1957) cognitive dissonance theory, which postulates that people have a strong tendency to interpret their own behaviors and beliefs in a way that maintains their good and consistent self-image (Aronson, 
1969; Thibodeau \& Aronson, 1992). That is, behaving in a way that is inconsistent with one's beliefs (or cognition) induces cognitive dissonance, which will threaten one's positive self-image and which, in turn, causes negative affect (Harmon-Jones, 2000). These unpleasant emotions motivate the person to try to reduce the dissonance and to achieve consonance between behaviors and beliefs (Festinger, 1957; Harmon-Jones, 2000). Thus, the cognitive dissonance perspective indicates that the source of unpleasant emotions arises from the discrepancy between beliefs and behaviors.

Under escalation situations, choosing to withdraw inevitably forces individuals to admit that their past decision was incorrect, which will lead to cognitive dissonance (i.e., behaving in a way that is inconsistent with their prior beliefs). Accordingly, "what better way to (re)affirm the correctness of those earlier decisions than by becoming even more committed to them?’(Brockner, 1992, p. 40). That is, individuals tend to behave in a way that minimizes the belief-behavior discrepancy and hence the experience of negative affect. In other words, the negative affect resulting from the belief-behavior discrepancy prevents individuals from performing against their prior beliefs (i.e., they continue the prior course of action). Thus, unlike the coping perspective, dissonance theory suggests that people reduce unpleasant emotions through escalation of commitment.

Note, however, that from the dissonance perspective, it is predicted that this positive relationship should be less pronounced when one is not responsible for the prior decision. The negative affect associated with cognitive dissonance will result only when there is a discrepancy between one's beliefs and behaviors; that is, when the inconsistency is relevant to the self-concept (Thibodeau \& Aronson, 1992). No cognitive dissonance will be experienced when the current behavior does not coincide with others' beliefs. When the failing course of action is initiated by another person, choosing to quit does not pose threats to the self-image of the current decision maker. In other words, the need to escalate so as to reduce the negative affect due to cognitive dissonance is minimal. In sum, on the basis of the cognitive dissonance perspective, we posit the following 
hypothesis (see Figure 1c, right panel):

Hypothesis 3: There is a Negative Affect $\times$ Responsible interaction effect on escalation of commitment. When one is personally responsible for a failing decision, there is a positive correlation between negative affect and escalation. When one is not personally responsible for a failing decision, this positive correlation is significantly reduced.

\section{Summary of the Three Perspectives}

Table 1 summarizes the key features and predictions derived from each of the three perspectives discussed above. Each proposes that negative affect plays a role in escalation of commitment, though from a different locus. The coping perspective suggests that negative affect induced by receiving negative, self-relevant feedback leads people to be more likely to withdraw from the current situation. The depressive realism perspective suggests that people with a high level of negative affect are generally more realistic and hence are less likely to be subjected to decision biases. The cognitive dissonance perspective suggests that the negative affect as a result of behavior-belief discrepancy will prevent individuals from revising a prior decision and they are thus forced to escalate.

Insert Table 1 about here

\section{The Present Study}

In this paper, we pit the foregoing three perspectives against each other in testing the relation between negative affect and escalation of commitment. Testing the above hypotheses is important because the results will enhance managerial understanding of the emotional core of escalation of 
commitment. We tested these hypotheses in three studies, each with a unique escalation context. Employing the conventional scenario paradigm in the escalation literature and operationalizing negative affect in terms of Neuroticism, we tested the above hypotheses in a resource allocation context (Study 1) and a selection and performance appraisal context (Study 2). We then extended the investigation to an experiment that placed participants in a simulated escalation situation where they received real consequences for their decisions (Study 3). Study 3 enabled us to capture the momentary affect induced by the escalation situation.

Study 1

Method

Participants and procedure. $\quad$ Two hundred and forty-seven undergraduate students (120 men and 127 women), enrolled in Organizational Behavior classes, participated in Study 1. Their average age was 20.46 (ranging from 18 to 24). All were randomly assigned to either the personally responsible condition or the personally non-responsible condition. Thus, there was one between-participant factor (i.e., personal responsibility).

Questionnaires were administered to participants in a large lecture theater. They were asked to complete the questionnaires by carefully reading a short scenario as if it were real. After indicating their willingness to continue the project, participants were given a questionnaire on which they were asked questions on Neuroticism, sense of responsibility, knowledge of financial decision-making, and other demographic information.

Decision task. $\quad$ The escalation task was the "blank radar plane” case from Arkes and Blumer (1985), which has been widely used to study escalation of commitment (e.g., Conlon \& Garland, 1993; Garland, 1990; Garland \& Conlon, 1998; Moon, 2001a, 2001b). Two versions (personally responsible vs. personally non-responsible) were developed. The personally responsible 
version was as follows, with information given in the personally non-responsible condition included in parentheses:

"You are (Frank was) the Vice President of Operations for a mid-sized high-tech manufacturing firm.

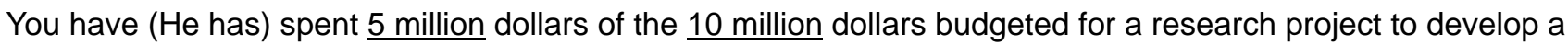
radar-scrambling device that would make a ship undetectable by conventional radar, i.e., in effect a radar-blank ship. The engineering department has informed you that the project is $\underline{90 \%}$ complete.

(Frank retired after starting this project and you were promoted to replace Frank as the Vice President). However, you have just discovered that another firm has already begun marketing a similar product with a much better design: It takes up less space and is much easier to operate than your design. The decision you face now is either to (a) quit this project and use the rest of the money to invest in another new product or (b) authorize the next 1 million to continue the current project".

After reading the scenario, participants were asked to indicate their willingness to continue the project by giving a probability rating ranging between 0\% (absolutely no) and 100\% (absolutely yes). In line with previous studies (Conlon \& Garland, 1993; Garland, 1990; Garland \& Conlon, 1998; Moon, 2001b), this willingness rating served as the index of escalation of commitment.

Measures. $\quad$ Neuroticism was measured by a 13-item subscale from the Adjective Check List of the Big Five Inventory ( $\underline{\alpha}=.82$; Gough \& Heibrun, 1983; McCrae \& Costa, 1987). Responses were made on a 7-point rating scale, ranging from 1 "strongly disagree” to 7 "strongly agree.”

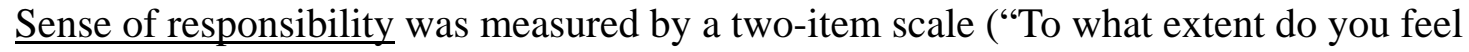
responsible for the previous investment of 5 million dollars?” and “To what extent do you feel responsible for starting this project?”) adapted from Conlon and Park (1987; $\underline{\alpha}=.79)$. Responses were made on a 7-point rating scale, ranging from 1 "to a very small extent" to 7 "to a very large extent.” This variable was included as a check of the responsibility manipulation. 


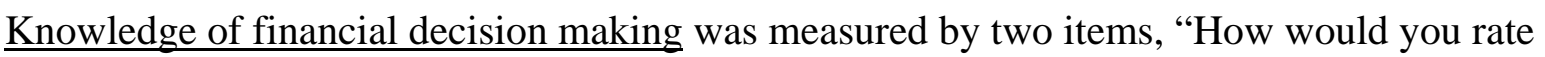
your capability to make a financial decision?” and “How would you rate your knowledge of financial decision-making?” with a 7-point Likert scale $(\underline{\alpha}=.79)$. This variable was treated as a control variable in subsequent analyses because people may escalate more when they believe that they are more knowledgeable in that domain (Whyte et al., 1997).

Other factors, including absolute sunk costs, relative sunk costs, and degree of project completion, that have been shown to have effects on escalation of commitment, were controlled by holding these variables constant for all participants. It has been shown that there are age and gender differences in risk-taking behavior (Slovic, 1966; Vroom \& Pahl, 1971). As escalation of commitment has been viewed as a risk-taking behavior (Brockner, 1992; Whyte, 1986; Wong, in press), subsequent analyses also included gender and age of the participants as control variables. $\underline{\text { Results and Discussion }}$

$\underline{\text { Manipulation checks. }} \quad$ Participants in the responsible condition felt stronger responsibility ( $\underline{\mathrm{M}}$ $=4.93, \underline{\mathrm{SD}}=1.05)$ than did those in the non-responsible condition $(\underline{\mathrm{M}}=4.40, \underline{\mathrm{SD}}=1.38), \underline{\mathrm{F}}(1,245)$ $=11.58, \underline{\mathrm{MSE}}=1.49, \underline{\mathrm{p}}<.001 . \quad$ The result indicates that the manipulation was successful in Study 1. Participants in the responsible condition had a stronger willingness to continue the project $(\underline{\mathrm{M}}=$ $62.59, \underline{\mathrm{SD}}=25.26)$ than did those in the non-responsible condition $(\underline{\mathrm{M}}=55.96, \underline{\mathrm{SD}}=25.99), \underline{\mathrm{F}}(1$, $245)=4.13, \underline{\mathrm{MSE}}=656.87, \underline{\mathrm{p}}<.05 . \quad$ This finding replicated results from previous studies (Conlon \& Park, 1987; Staw, 1976), indicating that the typical escalation bias occurred in this study.

Test of hypotheses. $\quad$ Means, standard deviations, and zero order correlations of the variables of interest are presented in Table 2, which shows the trend of a negative Neuroticism-Escalation correlation, $\underline{\mathrm{r}}=-.09$, $\underline{\mathrm{ns}}$. Hierarchical regression analyses were conducted to test the unique contribution of Neuroticism as well as the Neuroticism $\times$ Responsibility interaction effects on escalation. The regression results are given in Table 3. 
Insert Tables 2 \& 3 about here

First, we discuss the overall model. In Step 1, we entered Age, Gender, and Knowledge of Financial Decision-Making to control for their possible effects on escalation of commitment. In Step 2, we entered Neuroticism and Responsibility, which jointly contributed a significant portion of the accounted variance, $\Delta \underline{\mathrm{R}}^{2}=.03, \underline{\mathrm{p}}<.05$. Only Responsibility was significantly related to the ratings, $\underline{\beta}=.13, \underline{\mathrm{p}}<.05$. In Step 3, we entered the Neuroticism $\times$ Responsibility interaction into the equation. Following the advice of Aiken and West (1991), the Neuroticism $\times$ Responsibility interaction term was computed by multiplying the standardized score of Neuroticism and the standardized score of Responsibility of each participant. The interaction term had a significant effect on escalation of commitment, $\Delta \underline{\mathrm{R}}^{2}=.02, \underline{\beta}=-.14, \underline{\mathrm{p}}<.05$.

To understand the pattern of the Neuroticism $\times$ Responsibility interaction, we conducted two separate Neuroticism-Escalation correlations. A negative Neuroticism-Escalation relationship was found in the responsible condition $(\underline{r}=-.24, \underline{p}<.01)$. The Neuroticism-Escalation correlation, however, was not significant in the non-responsible condition $(\underline{\mathrm{r}}=.05, \underline{\mathrm{ns}})$. Figure 2 (left panel) shows the Neuroticism $\times$ Responsibility interaction pattern of Study 1, which was consistent with Hypothesis 1, while not supporting Hypotheses 2 and 3.

Insert Figure 2 about here

In sum, the results indicate that the Neuroticism $\times$ Responsibility interaction pattern is consistent with the predictions derived from the coping perspective. People with high Neuroticism, presumably because of their stronger experience of negative affect, have less tolerance for negative 
situations than do people with low Neuroticism, and hence are less likely to stick with the same course of action when it appears to be failing. However, because a personally non-responsible decision is less likely to lead to a negative affect (i.e., it is not self-relevant), there is no difference in escalation of commitment across different levels of Neuroticism in this situation. In the next study, we attempt to replicate the above pattern of results in a selection-appraisal context.

Study 2

Method

Participants, design, and procedure. $\quad$ One hundred and seventy-five undergraduate students (47 men and 128 women), enrolled in Organizational Behavior classes, participated in Study 2. Their average age was 19.5 (ranging from 18 to 24). All were randomly assigned to either a personally responsible condition or a personally non-responsible condition. The procedure was identical to that in Study 1.

Procedure and decision task. $\quad$ The decision task was the scenario from the Adams and Smith case developed by Staw (1976) and modified to a personnel selection context. The scenario was divided into three phases. In Phase 1, participants were informed that the case was designed to examine the effectiveness of personnel decision-making. They were then given either a personally responsible version or a personally non-responsible version of the scenario. The description of the personally responsible version is as follows:

"This questionnaire is about a personnel decision case describing a selection in $\underline{1996}$. In this case, you are the Sales Manager at the Adams \& Smith Company and are required to select the best candidate to join your team. After many rounds of eliminations, there are only two applicants for final consideration. You have to select $\underline{\mathrm{ONE}}$ of them to join your team. You are required to select the one who can contribute to the sales and earnings in your team." 
Participants were provided with information on Candidate A and Candidate B for reference. The information included the previous sales and earnings records of the two candidates and brief descriptions of their backgrounds. They were informed that the final decision they made in 1996 was to hire Candidate A.

In Phase 2, all participants were required to complete items measuring their sense of responsibility for this hiring. This measure was added to check for the responsibility manipulation. Phase 3 was started after they completed the questionnaire. In Phase 3, participants in the responsible condition were instructed that:

"It is now $\underline{2001}$, five years after the selection decision. You are required to give a performance appraisal to Candidate A, whom you selected five years ago."

A table summarizing Candidate A’s contributions to the sales and earnings after joining was given to all participants. The table indicated that the performance of Candidate A was poor (see Appendix A). Participants were then asked to make the performance appraisal by answering questions about Candidate A’s performance.

The description of the non-responsible version was as follows:

(In Phase 1) "This questionnaire is about a personnel decision case describing a selection in $\underline{1996 .}$. In this case, Frank, the Sales Manager at the Adams \& Smith Company, is required to select the best candidate to join his team. You are a member of Frank's team but you are not at all involved in the selection decision. After many rounds of eliminations, there are only two applicants for final consideration. Frank has to select $\underline{\mathrm{ONE}}$ of them to join your team. He is required to select the one who can contribute to the sales and earnings in your team." 
(In Phase 3) "It is now 2001, five years after the selection decision. Frank has retired and you have been promoted to be the Sales Manager at the A\&S company. You are required to give a performance appraisal to Candidate A, whom Frank selected five years ago."

Measures. Four items (see Appendix B) in 7-point Likert format were developed to measure participants' evaluations of the performance of the selected candidate $(\underline{\alpha}=.82)$. Following prior studies (Bazerman et al., 1982; Schoorman, 1988), escalation of commitment to the prior hiring decision is manifested in terms of the extent to which evaluation scores of the hired employee are elevated.

As in Study 1, both the Neuroticism scale and Personal responsibility scale were used in Study 2 $(\underline{\alpha} s>.75)$.

\section{$\underline{\text { Results and Discussion }}$}

Manipulation checks. We repeated the analysis sequence in Study 1 for the manipulation checks. First, participants in the responsible condition felt stronger responsibility $(5.40, \underline{\mathrm{SD}}=.78)$ than did those in the non-responsible condition (4.70, $\underline{\mathrm{SD}}=1.04), \underline{\mathrm{F}}(1,173)=25.27, \underline{\mathrm{MSE}}=.84, p$ $<.001$, indicating that the manipulation was successful in this study. Second, participants in the responsible condition gave significantly higher performance ratings $(3.77, \underline{\mathrm{SD}}=.88)$ than did those in the non-responsible condition $(3.47, \underline{\mathrm{SD}}=.94), \underline{\mathrm{F}}(1,174)=4.66, \underline{\mathrm{MSE}}=.83, \underline{\mathrm{p}}<.05$. This replicated prior results on escalation of commitment in the selection and performance appraisal context (Bazerman et al, 1982; Schoorman, 1988).

Test of hypotheses. $\quad$ Means, standard deviations, and zero-order correlations of variables of interest are presented in Table 4, which shows a significant negative Neuroticism-Escalation correlation, $\underline{\mathrm{r}}=-.18, \underline{\mathrm{p}}<.05$. Hierarchical regression analyses were conducted to test the unique contribution of Neuroticism as well as the Neuroticism $\times$ Responsibility interaction effects on 
escalation of commitment. The regression results are given in Table 5.

Insert Tables 4 \& 5 about here

First, we discuss the overall model. In Step 1, we entered Age and Gender to control for their possible effects on escalation of commitment. In Step 2, we entered Neuroticism and Responsibility, which jointly contributed a significant portion of the accounted variance, $\Delta \underline{\mathrm{R}}^{2}=.06, \underline{\mathrm{p}}<.05$. Neuroticism was significantly and negatively related to performance evaluation, $\underline{\beta}=-.20, \underline{p}<.05$, and Responsibility was significantly and positively related to performance evaluation $\underline{\beta}=.16, \underline{\mathrm{p}}<.05$. In Step 3, we entered the centered Neuroticism $\times$ Responsibility interaction term, which had a significant effect on performance evaluation, $\Delta \underline{\mathrm{R}}^{2}=.06, \underline{\beta}=-.24, \underline{\mathrm{p}}<.01$.

To understand the pattern of the Neuroticism $\times$ Responsibility interaction, we conducted two separate Neuroticism-Escalation correlations. The negative Neuroticism-Escalation relationship was again found in the responsible condition $(\underline{r}=-.43, \underline{p}<.01)$. The Neuroticism-Escalation correlation, however, was not significant in the non-responsible condition $(\underline{r}=.05$, $\underline{\text { s }})$. Figure 2 (middle panel) shows the Neuroticism $\times$ Responsibility interaction pattern of Study 2. This interaction pattern was consistent with Hypothesis 1, further supporting the coping perspective. Again, there was no support for Hypotheses 2 and 3.

In sum, we replicated the Neuroticism $\times$ Responsibility interaction pattern in Study 1 . This pattern suggests that the role played by negative affect (manifested as Neuroticism) in escalation behavior is consistent with the hypothesis derived from the coping perspective.

Study 3

One concern with respect to Studies 1 and 2 was that there was no real consequence from the 
decisions made by the participants, so that the scenario per se might not be sufficient to arouse the on-line negative affect. To address this concern, we conducted a laboratory study in which participants' decisions were related to the amount of rewards they would actually receive. In contrast to the use of the trait negative affect in Studies 1 and 2, Study 3 looked at a momentary state of negative affect (e.g., Portello \& Long, 2001; Weiss et al., 1999; Weiss \& Kurek, 2003). This approach seems to be particularly useful in capturing the ebbs and flow of emotional reaction to the real consequences of decision-making, enabling us to directly capture the instant psychological effects of negative affect on escalation of commitment.

In Study 3, participants first invested some effort and money in performing either a visual judgment task or a numerical judgment task in order to gain points to win a jackpot. To resemble the two defining features of a typical escalation situation, namely "negative feedback” and “sunk costs” (Brockner 1992; Brockner et al., 1986; Staw, 1997), participants were led to realize that they had done very poorly on the task (negative feedback) and the points they gained would be useless if they did not continue the same task (sunk cost). They were then informed that they could switch to another judgment task or could continue the same task. Escalation of commitment was manifested as the extent to which they continued to keep investing in the same judgment task they had chosen at the outset (see Brockner et al., 1986 for a similar laboratory setting).

In addition, participants might vary in self-efficacy on the two judgment tasks. Past research has shown that people are more likely to escalate when their self-efficacy is high than when it is low (Whyte et al., 1997). To rule out the possible effects due to self-efficacy, we measured it at the very beginning of the experiment and then treated it as a control variable in the subsequent analyses.

\section{Method}

Participants, design, and procedure. $\quad$ Forty undergraduate students (20 men and 20 women) 
participated in this study. Their average age was 21.83 (ranging from 19 to 39). All were randomly assigned to either a personally responsible condition or a personally non-responsible condition. Thus, there was one between-participant factor (i.e., personal responsibility).

When the participant arrived at the room, he/she met another participant (a confederate) and an experimenter. The experimenter explained that the experiment required two individuals to form a team and that each team had a possibility to win up to $\$ 50$ depending on the group performance. The lump sum would be split evenly between them. Then the participant was seated individually in a quiet laboratory room and completed the whole experiment on a computer.

All participants were led to believe that their computers were connected with those of their confederates; that the experiment consisted of "three” phases; and that the player to participate in each phase was "randomly" assigned and each of them would be involved at least once. They were informed that the contents of the three phases were related to each other. Therefore, they should observe the responses of their partners even when they were not taking part in a particular phase.

At the beginning of Phase 1, each team was given $\$ 15$ as capital. They were told that the player in Phase 1 would choose one of the two available games to play for ten trials. Each trial cost 50 cents. Thus, the team would spend $\$ 5$ on one of the games in Phase 1 . The performance on each trial would determine the scores the team would get. Accordingly, once they accumulated 1000 points (see Appendix C for scoring), they would get a jackpot of $\$ 50$.

Detailed descriptions of the two games were then given to all participants (see Appendix C). They completed four items measuring their self-efficacy on the two games. Next, the computer “randomly” assigned the player of Phase 1 (it was actually determined by the responsibility manipulation explained below). The player selected one game and finished the ten trials following three practice trials.

At the end of Phase 1, the computer generated a summary of the player's performance and the 
points earned in the ten trials as well as the amount of money invested so far (i.e., \$5). The feedback, which was in fact manipulated to be independent of the actual performance, had been intentionally programmed to foster the impression that the players in Phase 1 had done poorly. All participants were told that the players accumulated only $11.4 \%$ of points required for a jackpot. Note that the results were so extremely negative that the player came close to the points needed to win the jackpot (see also Brockner et al., 1986 for a similar method of introducing negative performance feedback). The computer prompted the participants to complete a scale measuring their current experience of negative affect. That was the end of Phase 1. Thus, in this phase, we introduced two essential elements of an escalation situation, negative feedback and sunk costs (i.e., money spent on one of the two games).

In Phase 2, the computer always assigned the participants to be the player for this phase. They were asked how they would allocate the remaining $\$ 10$. They could spend all the money on one of the two games. Alternatively, they might split the money into two portions and allocate them to the two games. Regardless of their allocation, the cost of each trial for either game was 50 cents.

All participants were further informed that the points earned in the two games were independent such that points earned in the two accounts were not allowed to be inter-transferred. Thus, the points accumulated in Phase 1 could not be transferred to the other account. When they had amassed 1000 points in any one of the accounts, they would win the $\$ 50$ jackpot. If they performed well, they had the opportunity to earn a jackpot for each account. The computer recorded the participants' allocation decisions. Then, the participants answered a question that measured their sense of responsibility for the outcome in Phase 1. After that, the computer program terminated and that was the end of the experiment. The participants were debriefed (there was never a Phase 3) and thanked. In a nutshell, Phase 2 introduced the third element of an escalation situation - the decision maker was given a chance to either continue further investment (i.e., to invest in the same 
game as in Phase 1) as an attempt to recover the sunk cost or to withdraw entirely from the previous action (i.e., not to invest in the same game as in Phase 1).

Personal responsibility was manipulated by the assignment of the player in Phase 1 . To recap, the player in Phase 2 was always the participant. In the responsible condition, the computer was programmed to assign the participant to be the player in Phase 1. This arrangement ensured that the person who made the initial decision in Phase 1 (i.e., in which game he/she would invest) was always the same person who made the subsequent decision in Phase 2. In the non-responsible condition, participants were led to believe that the confederate completed Phase 1. This arrangement ensured that the participants were not responsible for the initial decision.

In order to control all the choice information and game responses that emerged from Phase 1 identical across the responsible and the non-responsible conditions, we employed a "yoked participant” technique. In the responsible condition, we recorded the participants' choices of game and all trial responses in Phase 1. This information was then presented to the subsequent "yoked" participants in the non-responsible condition. Specifically, in Phase 1, the non-responsible participants were informed of the task that their partner had selected, which was actually the choice of the yoked participant in the personally responsible condition. They were then forced to observe all the responses of the yoked participant. This was done by requiring them to press a "continue" button on the computer screen to proceed to the next trial. Thus, in essence, the information shown in Phase 1 for the responsible condition was the same as that in Phase 1 for the responsible condition. Measures. The state negative affect was measured by the Unpleasant Affect scale $(\underline{\alpha}=.75)$, which has been used by scholars studying current affect (Feldman Barrett \& Russell, 1998; Yik et al., 2002). Respondents were asked to assess their “current affect” using four items, namely miserable, $\underline{\text { troubled, unhappy, dissatisfied. }}$ Responses to these adjective items were made on a 5-point rating scale, ranging from 1 “not at all” to 5 “extremely”. 
$\underline{\text { Escalation of commitment was measured by the amount of money allocated to play the same }}$ game selected in Phase 1. Sense of responsibility was measured to check the manipulation of personal responsibility. It was measured by a single item (“To what extent do you feel responsible for the team performance in Phase 1?”) on a 5-point rating scale, ranging from 1 “to a very small extent” to 5 "to a very large extent."

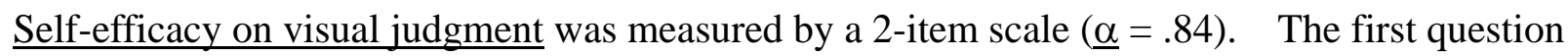
asked “How would you describe your capability in visual judgment”, ranging from 1 "very weak” to 5 “very strong." The second question asked "How confident are you in winning the jackpot by the visual judgment task?”, ranging from 1 “not confident” to 5 “very confident”.

Self-efficacy on numerical judgment was measured by a 2-item scale ( $\underline{\alpha}=.77)$. The first question asked “How would you describe your capability in numerical judgment”, ranging from 1 “very weak" to 5 "very strong." The second question asked "How confident are you in winning the jackpot by the numerical judgment task?”, ranging from 1 “not confident” to 5 “very confident”). $\underline{\text { Results and Discussion }}$

Manipulation checks. $\quad$ We repeated the analysis sequence in Study 1 for the manipulation checks. Participants in the responsible condition felt stronger responsibility $(3.65, \underline{\mathrm{SD}}=.1 .04)$ than did those in the non-responsible condition (1.70, $\underline{\mathrm{SD}}=1.08), \underline{\mathrm{F}}(1,38)=33.8, \underline{\mathrm{MSE}}=1.13, \underline{\mathrm{p}}<.001$, indicating that the manipulation was successful in this study. The mean amount of money spent on the same judgment task in the responsible condition $(5.74, \underline{\mathrm{SD}}=2.62)$ was significantly more than that in the non-responsible condition (3.36, $\underline{\mathrm{SD}}=2.3), \underline{\mathrm{F}}(1,38)=9.24, \underline{\mathrm{MSE}}=48.55, \underline{\mathrm{p}}<.005$. This finding indicates that escalation of commitment was found in the present study.

Test of hypotheses. $\quad$ Means, standard deviations, and zero-order correlations of variables of interest are presented in Table 6, which shows a significant interaction between money spent on the same task and responsibility, $\underline{\mathrm{r}}=.44, \underline{\mathrm{p}}<.05$. This correlation indicates that people tended to spend 
more on the same task when they were responsible for the prior performance than when they were not responsible for it, replicating the responsibility effects on escalation of commitment (Conlon \& Park, 1987; Staw, 1976). Hierarchical regression analyses were conducted to test the unique contribution of Unpleasant Affect as well as the Unpleasant Affect $\times$ Responsibility interaction effects on escalation of commitment. We tested three models here with the same analysis sequence described in Study 1. The regression results are given in Table 7.

Insert Tables 6 \& 7 about here

First, we discuss the overall model. In Step 1, we entered Age, Gender, Self-efficacy on visual judgment, and Self-efficacy on numerical judgment to control for their possible effects on escalation of commitment. In Step 2, we entered Unpleasant Affect and Responsibility, which jointly contributed a significant portion of the accounted variance in Step $2, \Delta \underline{R}^{2}=.16, \underline{p}<.05$. Responsibility was significantly and positively related to the amount of money spent on the same judgment task, $\underline{\beta}=.41, \underline{p}<.01$. In Step 3, we entered the centered Unpleasant Affect $\times$ Responsibility interaction term, which had significant effects on escalation of commitment, $\Delta \underline{\mathrm{R}}^{2}$ $=.09, \underline{\beta}=-.34, \underline{p}<.05$.

To understand the pattern of the Unpleasant Affect $\times$ Responsibility interaction effect, we conducted two separate Unpleasant Affect-Escalation correlations. In the responsible condition, the correlation was -.34. In the non-responsible condition, the correlation was .16. Although the -.34 correlation coefficient in the responsible condition was quite impressive, it was not statistically significant, probably due to the low statistical power of the current study (i.e., 20 participants in each condition). Nonetheless, the significant Unpleasant Affect $\times$ Responsibility interaction indicates that the strengths of the relationship between Unpleasant Affect and escalation of commitment in the 
responsible condition is significantly different from that in the non-responsible condition. This pattern of interaction, as shown in Figure 2 (right panel), is consistent with the interaction pattern predicted by the coping perspective.

In sum, the Unpleasant Affect $\times$ Responsibility interaction pattern replicated those found in Studies $1 \& 2$, further strengthening the notion that the role played by emotion in escalation behavior is the one derived from the coping perspective. More important, the Negative Affect $x$ Responsibility interactions were found in an investment context typically used in escalation research (Study 1), in a less typical selection-appraisal situation (Study 2), and in a condition with real consequences from participants’ decisions (Study 3). Thus, Studies 1 to 3 point to the generality of the Negative Affect $\times$ Responsibility interaction effects on escalation of commitment.

\section{General Discussion}

\section{$\underline{\text { Implications for Organizational Research }}$}

In this paper, we offer a contribution to the understanding of escalation of commitment by pointing out that the emotional aspects of making decisions under escalation situations should not be neglected. As an initial step in understanding how emotion is related to escalation of commitment, we examined the interaction between negative affect and personal responsibility. The big picture that emerges from the three studies from different contexts is consistent with the coping perspective. Specifically, this perspective posits that when a prior and personally responsible decision receives negative feedback, a person's negative affect increases the likelihood of adopting an avoidance/withdrawal strategy to cope with the negative situation (Endler \& Parker, 1990; Miller et al., 1988). With this strategy, people with high Neuroticism (and hence should experience stronger negative affect) are less likely than people with low Neuroticism to stick with the same investment option (Study 1) or with the same selection decision (Study 2). In addition, people experiencing 
stronger momentary negative affect exhibit less escalation of commitment in situations in which their decisions have real consequences (Study 3). These three studies suggest that future studies specifying the emotional processes and emotional components that underline escalation of commitment would be useful for a full understanding of escalation of commitment.

In addition, the three studies reported here also add to the growing body of literature focusing on individual differences in escalation of commitment (Moon 2001b; Schaubroeck \& Williams, 1993; Whyte et al., 1997). Empirical inconsistencies have been evident with respect to individual differences in escalation of commitment. On the one hand, Staw and Ross (1978) found no impacts of dogmatism, tolerance for ambiguity, or self-esteem on escalation of commitment. Levi (1981, cited in Whyte et al., 1997) reported that locus of control, mania, and depression were not related to escalation of commitment. These findings appear to suggest that there is no clear relationship between individual difference variables and escalation of commitment. On the other hand, more recent studies showed that escalation of commitment was related to self-esteem (Knight \& Nadel, 1986), self-efficacy (Whyte et al., 1993), Type A personality (Schaubroeck and Williams, 1993), and two facets of conscientiousness (Moon, 2001b). The present research supports the idea that there are individual differences in escalation tendency. It reveals that people who are generally more neurotic are less likely to stick with their previous decision.

The present research showed no evidence for the depressive realism perspective (i.e., Hypothesis 2). In a study using managerial simulations, Staw and Barsade (1993) also failed to obtain evidence for this perspective. These findings together indicate that the "sadder-but-wiser" effect might not be very robust and might not be easy to generalize to other decision tasks (Dunning \& Story, 1991; Shrauger et al., 1998). Another possible reason for why results from the present research and those by Staw and Barsade (1993) did not support the depressive realism perspective is that we used general emotion measures (i.e., Neuroticism and Unpleasant Affect in this study and 
Positive Affect in Staw \& Barsade's) to test the hypotheses. These measures, however, might be too general to capture the specific emotion, namely depression, that leads to the sadder-but-wiser effect. Further studies could examine the relationship between depression, instead of a general emotion, and performance in managerial decisions.

The present research also showed no evidence for the cognitive dissonance perspective (i.e., Hypothesis 3). These findings, however, should not be regarded as challenging the argument that cognitive dissonance is a primary source for escalation of commitment, a notion that has been supported by a large body of research (Conlon \& Park, 1987; Brockner, 1992; Staw, 1976, 1997). Indeed, the present research consistently revealed that personal responsibility effects, which have been characterized as primary evidence for cognitive dissonance (Brockner, 1992; Staw, 1976; Staw et al., 1995), remained significant after the Negative Affect $\times$ Responsibility interaction terms were entered into the regression equations (see Tables $3,5, \& 7$ ). One possible way to reconcile the coping perspective with the cognitive dissonance perspective is that people may anticipate and experience different sources of negative affect under escalation situations. Negative affect may stem from the negative feedback one will get if one continues the same course of action (e.g., sense of failure, regret for prior decision, etc.), while a negative affect may also arise from (potential) cognitive dissonance if one quits the previous course of action. It may be true that when people are responsible for the initial decision, the force pulling people to stick with the same course of action as a result of cognitive dissonance is outweighed by the counterforce of avoiding the even stronger negative affect that may result. Thus, there may be a net "withdrawal” effect of negative affect in the personally responsible condition, resulting in the interaction pattern found in Studies 1 to 3.

\section{$\underline{\text { Practical Implications }}$}

Typically, escalation research has identified negative feedback to prior decisions and personal responsibility as the two essential determinants that jointly induce escalation of commitment 
(Brockner, 1992; Staw, 1976). Thus, the debiasing strategies of escalation of commitment suggested thus far have focused primarily on how the responsibility effects can be attenuated (Simonson \& Staw, 1992) or eliminated altogether (Staw, 1982). For example, in suggesting how to reduce escalation bias, Staw (1982) stated "when organizations have experienced losses from a given investment or course of action, they should rotate or change those in charge of allocating resources” (p. 114).

One practical implication of the present research is the identification of negative affect as a moderator of the responsibility effect on escalation of commitment. The present study shows that emotions substantially influence escalation behavior, suggesting that when eliminating personal responsibility is not viable, managers should take individual differences in negative affect into consideration. Special attention should be paid to the individuals with low Neuroticism who usually appear to be calm and capable of handling business turbulence. This "quiet” group consists of those who may become extremely vulnerable to falling into the trap of "throwing good money after bad.”

\section{Limitations and Future Research}

There are three limitations that may warrant additional investigation. First, we measured negative affect as a broad construct representing a variety of unpleasant emotions. Although this approach enables us to understand the general impact of negative affect on escalation of commitment, it may not reveal the specific emotional components that are responsible for the observed Negative Affect-Escalation relationship. The next step in a systematic investigation is to examine the relationships between the specific emotions (anxiety, regret, hostility, depression, etc.) and escalation of commitment.

Second, we did not include variables measuring coping strategies in the present study. Although we found that the Negative Affect $\times$ Responsibility interaction was consistent with the pattern 
predicted by the coping perspective, more direct evidence supporting the coping perspective should include measures on coping styles or strategies. By including coping variables, future research may examine if coping strategies mediate the affect effects on escalation under the responsible condition.

Another limitation of the present study was that we recruited undergraduate business students, who had limited experience in making financial and hiring decisions, as participants. Because the majority of studies on escalation of commitment employed scenario methods with student samples (Arkes \& Blumer, 1985; Moon, 2001a, 2001b; Staw, 1976; see Staw, 1997 for a discussion of using student samples), we believe that using student samples in highly controlled experiments as an initial step in examining the emotional aspects of escalation of commitment will make the present research and prior studies more comparable. This facilitates a direct comparison of the findings. Nonetheless, this approach may limit the generalizability of the findings to real-world settings and future research may seek further evidence for external validity by collecting data from the working population.

\section{$\underline{\text { Conclusion }}$}

In summary, the present study shows the importance of understanding the emotional aspects of escalation of commitment. In three different contexts, we found a negative correlation between negative affect and escalation of commitment under personally responsible conditions, whereas the correlations disappear under the personally non-responsible conditions. This interaction pattern is most consistent with the coping perspective. These findings not only increase our current understanding of how escalation of commitment is related to an individual's enduring emotional stability and his/her current emotional reactions, but they also offer insights from the coping literature into why negative affect is negatively related to escalation of commitment. Our findings also indicate that negative affect is not only important to traditional dependent variables in organizational research (e.g., job satisfaction, turnover intention, etc.), but is also important to organizational decision-making. 


\section{References}

Aiken, L. S., \& West, S. G. (1991). Multiple regression: Testing and interpreting interactions. Newbury Park, CA: Sage.

Alloy, L. B. \& Abramson, L. Y. (1979). Judgment of contingency in depressed and nondepressed students. Sadder but wiser? Journal of Experimental Psychology: General, 108, 441-485.

Alloy, L. B., \& Ahrens, A. H. (1987). Depression and pessimism for the future: Biased use of statistically relevant information in predictions for self and others. Journal of Personality and Social Psychology, 52, 366-378.

Arkes, H. \& Blumer, C. (1985). The psychology of sunk costs. Organizational Behavior and Human Decision Processes, 35, 124-140.

Arkes, H., Kung, Y.-H., \& Hutzel, L. (2002). Regret, valuation, and inaction inertia. Organizational Behavior and Human Decision Processes, 87, 371-385.

Aronson, E. (1969). The theory of cognitive dissonance: A current perspective. Advances in Experimental Social Psychology, 4, 1-34.

Baumeister, R. F. (1993). Understanding the inner nature of low self-esteem: Uncertain, fragile, protective, and conflicted. In R. Baumeister (Ed.), Self-esteem: The puzzle of low-regard (pp. 201-218). New York: Plenum Press.

Baumeister, R. F., Smart, L., \& Boden, J. M. (1996). Relation of threatened egotism to violence and aggression: A dark side of high self-esteem. Psychological Review, 103, 5-33.

Bazerman, M. H. (1994). Judgment in managerial decision making (3rd ed.). New York: John Wiley.

Bazerman M. H., Beekun, R. I., \& Schoorman, F. D. (1982). Performance evaluation in a dynamic context: A laboratory study of the impact of prior commitment to the ratee. Journal of Applied Psychology, 67, 873-876.

Bazerman, M., Tenbrunsel A. E., \& Wade-Benzoni K. (1998). Negotiating with yourself and losing: Making decisions with competing internal preferences. Academy of Management Review, 23, 225-241.

Bohle, P., \& Tilley, A. J. (1993). Predicting mood change on night shift. Ergonomics, 36, 125-133.

Brief. A. P., Burke, M. J., George, J. M., Robinson, B. S., \& Webster, J. (1988). Should negative affectivity remain an unmeasured variable in the study of job stress? Journal of Applied Psychology, 73, 193-198.

Brief, A. P., Butcher, A. H., \& Roberson, L. (1995). Cookies, disposition, and job attitudes: The 
effects of positive mood-inducing events and negative affectivity on job satisfaction in a field experiment. Organizational Behavior and Human Decision Process, 62, 55-62.

Brief, A. P., \& Weiss, H. M. (2002). Organizational behavior: Affect in workplace. Annual Review of Psychology, 53, 279-307.

Brockner, J. (1992). The escalation of commitment to a failing course of action: Toward theoretical progress. Academy of Management Review, 17, 39-61.

Brockner, J., Houser, R., Birnbaum, G., Lloyd, K., Deitcher, J., Nathanson, S., \& Rubin, J. Z. (1986). Escalation of commitment to an ineffective course of action: The effect of feedback having negative implications for self-identity. Administrative Science Quarterly, 31, 109-126.

Brockner, J., Shaw, M. C., \& Rubin, J. Z. (1979). Factors affecting withdrawal from an escalating conflict: Quitting before it's too late. Journal of Experimental Social Psychology, 15, 492-503.

Brown, G. W. (1986). Etiology studies and illness behavior. In S. McHugh \& T. Vallis (Eds.), Illness behavior: A multidisciplinary model (pp. 331-342). New York: Plenum Press.

Conlon, D. E., \& Garland, H. (1993). The role of project completion information in resource allocation decisions. Academy of Management Journal, 36, 402-413.

Conlon, E. J., \& Park, J. M. (1987). Information requests in the context of escalation. Journal of Applied Psychology, 72, 344-350.

Costa, P. T., Jr., \& McCrae, R. R. (1980). Influence of extraversion and neuroticism on subjective well-being: Happy and unhappy people. Journal of Personality and Social Psychology, 38, 668-678.

Costa, P. T., Jr., \& McCrae, R. R. (1984). Personality as a lifelong determinant of wellbeing. In C. Z. Malatesta, \& C. E. Izard (Ed.), Emotion in adult development (pp. 141-157). Beverly Hills: Sage.

Costa, P. T., Jr., \& McCrae, R. R. (1992). Revised NEO Personality Inventory (NEO PI-R) and NEO Five-Factor Inventory (NEO-FFI): Professional Manual. Odessa, FL: Psychological Assessment Resources.

Costa, P. T., Jr., \& McCrae, R. R. (1996). Mood and personality in adulthood. In C. M. S. H. McFadden (Ed.), Handbook of emotion, adult development, and aging (pp. 369-383). San Diego, California: Academic Press.

Diener, E., \& Emmons, R. A. (1984). The independence of positive and negative affect. Journal of Personality and Social Psychology, 47, 1105-1117.

Dunning, D., \& Story, A. (1991). Depression, realism, and the overconfidence effect: Are the sadder 
wiser when predicting future actions and events? Journal of Personality and Social Psychology, 61, 521-532.

Endler, N. S., \& Parker, J. D. (1990). Multidimensional assessment of coping: A critical evaluation. Journal of Personality and Social Psychology, 58, 844-854.

Eysenck, H. J. (1992). Four ways five factors are not basic. Personality and Individual Differences, $\underline{13,} 667-673$

Eysenck, H. J., \& Eysenck, M. W. (1985). Personality and individual differences. A Natural Science Approach. New York: Plenum Press.

Feldman Barrett, L. F., \& Russell, J. A. (1998). Independence and bipolarity in the structure of current affect. Journal of Personality and Social Psychology, 74, 967-984.

Festinger, L. (1957). A theory of cognitive dissonance. Evanston, IL: Row, Peterson.

Fineman, S. (2000). Emotion Arenas Revisited. In S. Fineman (Ed.), Emotion in organization. (pp. 1-24). London: Sage.

Heine, S. J., \& Lehman, D. R. (1999). Culture, self-discrepancies, and self-satisfaction. Personality and Social Psychology Bulletin, 25, 915-925.

Harmon-Jones, E. (2000). Cognitive dissonance and experienced negative affect: Evidence that dissonance increases experienced negative affect even in the absence of aversive consequence. Personality and Social Psychology Bulletin, 12, 1490-1501.

Garland, H. (1990). Throwing good money after bad: The effect of sunk costs on the decision to escalate commitment to an ongoing project. Journal of Applied Psychology, 75, 728-731.

Garland, H., \& Conlon, D. E. (1998). Too close to quit: the role of project completion in maintaining commitment. Journal of Applied Social Psychology, 28, 2025-2048.

Gough, H. G., \& Heilbrun, A. B., Jr. (1983). Adjective Check List manual. Palo Alto, CA: Consulting Psychologists Press.

Isen, A. M. (2000). Positive affect and decision making. In M. Lewis \& J. M. Haviland-Jones (Eds.), Handbook of emotions, 2nd (pp. 261-277). New York: Guilford

Izard, C. E., Libero, D. Z., Putname, P., \& Haynes, O. M. (1993). Stability of emotion experiences and their relations to traits of personality. Journal of Personality and Social Psychology, 64, 847-860.

Judge, T. A., Bono, J. E., Illies, R., \& Gerhardt, M. W. (2002). Personality and leadership: A qualitative and quantitative review. Journal of Applied Psychology, 87, 765-780.

Judge, T. A., \& Heller, D., \& Mount, M. K. (2002). Five-factor model of personality and job 
satisfaction: A meta-analysis. Journal of Applied Psychology, 87, 530-541.

Judge, T. A. \& Ilies, R. (2002). Relationship between personality to performance motivation: A meta-analytic review. Journal of Applied Psychology, 87, 797-807.

Kirby, S. L., \& Davis, M. A. (1998). A study of escalating commitment in principal-agent relationships: Effects of monitoring and personal responsibility. Journal of Applied Psychology, 83, 206-217.

Knight, P. A., \& Nadel, J. I. (1986). Humility revised: Self-esteem, information search, and policy consistency. Organizational Behavior and Human Decision Processes, 38, 196-206.

Kuiper, N. A. (1978). Depression and causal attributions for success and failure. Journal of Personality and Social Psychology, 4, 236-246.

Lam, S. S. K., Yik, M. S. M., \& Schaubroeck, J. (2002). Responses to formal performance appraisal feedback: The role of negative affect. Journal of Applied Psychology, 87, 192-201.

Lewinsohn, P. M., Mischel, W., Chaplin, W., \& Barton, R. (1980). Social competence and depression: The role of illusory self-perceptions. Journal of Abnormal Psychology, 89, 203-212.

Luce, M., Bettman, J., \& Payne, J. W. (1997). Choice processing in emotionally difficult decisions. Journal of Experimental Psychology: Learning, Memory, and Cognition, 23, 384-405.

McCrae, R. R., \& Costa, P. T., Jr. (1987). Validation of the five-factor model across instruments and observers. Journal of Personality and Social Psychology, 52, 81-90.

Martin, L. L., \& Tesser, A. (1996). Some ruminative thoughts. In R. S. Wyer Jr. (Ed.), Ruminative thoughts: Advances in social cognition (Vol., 9, pp. 1-47). Mahwah, NJ: Erlbaum.

Mellers, B. A. (2000). Choice and the relative pleasure of consequences. Psychological Bulletin, 126, 910-924

Meyer, G. J., \& Shack, J. R. (1989). Structural convergence of mood and personality: Evidence for old and new directions. Journal of Personality and Social Psychology, 57, 691-706.

Miller, S. M., Brody, D. S., \& Summerton, J. (1998). Styles of coping with threat: Implications for health. Journal of Personality and Social Psychology, 54, 142-148.

Moon, H. (2001a). Looking forward and looking back: Integrating completion and sunk-cost effects within an escalation-of-commitment progress decision. Journal of Applied Psychology, 86, 104-113.

Moon, H. (2001b). The two faces of conscientiousness: Duty and achievement striving in escalation of commitment dilemmas. Journal of Applied Psychology, 86, 535-540.

Nathanson, S., Brockner, J., Brenner, D., Samuelson, C., Countryman, M., Lloyd, M., \& Rubin, J. Z. 
(1982). Toward the reduction of entrapment. Journal of Applied Social Psychology, 12 , 193-208.

O’Brien, T. B., Delongis, A. (1996). The interactional context of problem-, emotion-, and relationship-focused coping: The role of the Big-Five personally factors. Journal of Personality, 64, 775-813.

Portello, J. Y., \& Long, B. C. (2001). Appraisals and coping with workplace interpersonal stress: A model for women managers. Journal of Counseling Psychology, 48, 144-156.

Sarason, I. G., Pierce, G. R., \& Sarason, B. R. (1996). Domains of cognitive interference. In I. G. Sarason, G. R. Pierce, \& B. R. Sarason (Eds.), Cognitive Interference: Theories, methods, and findings (pp. 139-152). Mahwah, NJ: Erlbaum.

Schaubroeck, J., Judge, T. A., \& Taylor, L. A. (1998). Influences of trait negative affect and situational similarity on correlation and convergence of work attitudes and job stress perceptions across two jobs. Journal of Management, 24, 553-576.

Schaubroeck, J., \& Williams, S. (1993). Type A behavior pattern and escalating commitment. Journal of Applied Psychology, 78, 862-867.

Schoorman, F. D., (1988). The escalation bias in performance appraisal: An unintended consequence of supervisor participation in hiring decisions. Journal of Applied Psychology, 73, 58-62.

Shrauger, J. S., Mariano, E., \& Walter, T. J. (1998). Depressive symptoms and accuracy in the prediction of future events. Personality and Social Psychology Bulletin, 24, 880-892.

Simonson, I., \& Staw, B. M. (1992). Deescalation strategies: A comparison of techniques for reducing commitment to losing courses of action. Journal of Applied Psychology, 77, 419-426.

Slovic, P. (1966). Risk-taking in children: Age and sex differences. Child Development, 37, 169-176.

Staw, B. M. (1976). Keep-deep in the big muddy: A study of escalating commitment to a chosen course of action. Organizational behavior and Human Performance, 16, 27-44.

Staw, B. M. (1981). The escalation of commitment to a course of action. Academy of Management Review, 6, 577-587.

Staw, B. M. (1982). Counterforces to change. In P. S. Goodman (Ed.), Change in organizations (pp. 87-121). San Francisco: Jossey-Bass.

Staw, B. (1997). The escalation of commitment: An update and appraisal. In Z. Shapira (Ed.), Organization decision making (pp. 191-215). New York: Cambridge University Press.

Staw, B. M., \& Barsade, S. G. (1993). Affect and managerial performance: A test of the sadder-but-wiser vs. happier-and-smarter hypotheses. Administrative Science Quarterly, 38, 
304-331.

Staw, B. M., Barsade, S. G., \& Koput, K. W. (1995). Escalation at the credit window: A longitudinal study of bank executives' recognition and write-off of problem loans. Journal of Applied Psychology, 82, 130-142.

Staw, B. M., \& Ross, J. (1978). Commitment to a policy decision: A multiheoretical perspective. Administrative Science Quarterly, 23, 40-64.

Staw, B. M., \& Ross, J. (1987). Behavior in escalation situations: Antecedents, prototypes, and solutions. In B. M. Staw \& L. L. Cummings (Eds.), Research in organizational behavior (Vol 9, pp. 39-78). Greenwich, CT: JAI Press.

Taylor, S. E., \& Brown, J. D. (1988). Illusion and well-being: A social psychological perspective on mental health. Psychological Bulletin, 103, 193-210.

Tellegen, A. (1985). Structures of mood and personality and their relevance to assessing anxiety, with an emphasis on self-report. In A. H. Tuma \& J. D. Maser (Eds.), Anxiety and Anxiety Disorders (pp. 681-706). Hillsdale, New Jersey: Erlbaum.

Terry, D. J. (1994). Determinants of coping: The role of stable and situational factors. Journal of Personality and Social Psychology, 66, 895-910.

Thibodeau, R., \& Aronson, E. (1992). Taking a closer look: Reassuring the role of self-concept in dissonance theory. Personality and Social Psychology Bulletin, 18, 591-602.

Tokar, D. M., Fischer, A. R., \& Subich, L. M. (1998). Personality and vocational behavior: A selective review of the literature, 1993-1997. Journal of Vocational Behavior, 53, 115-153.

Tykocinski, O. E., \& Pittman, T. S. (1998). The consequences of doing noting: Inaction inertia as avoidance of anticipated counterfactual regret. Journal of Personality and Social Psychology, 75, 607-616.

Vroom, V. H., \& Pahl, B. (1971). Relationship between age and risk taking among managers. Journal of Applied Psychology, 55, 399-405.

Walsh, J. P. (1995). Managerial and organizational cognition: notes from a trip down memory lane. Organizational Science, 6, 280-321.

Watson, D. (2000). Mood and temperament. New York, NY: Guilford Press.

Watson, D., \& Clark, L. A. (1984). Negative affectivity: The disposition to experience aversive emotional states. Psychological Bulletin, 96, 465-490.

Watson, D., \& Tellegen, A. (1985). Toward a consensual structure of mood. Psychological Bulletin, 98, 219-235. 
Weinstein, N. D. (1980). Unrealistic optimism about future life events. Journal of Personality and Social Psychology, 39, 806-820.

Weiss, W. M., Nicholas, J. P., \& Daus, C. S. (1999). An examination of the joint effects of affective experiences and job beliefs on job satisfaction and variations in affective experiences over time. Organizational Behavior and Human Decision Processes, 78, 1-24.

Weiss, H. M. (2002). Conceptual and empical foundations of tht estudy of affect at work. In R. G. Lord, R. J. Klimoski, \& R. Kanfer (Eds.), Emotions in the workplace: Understanding the

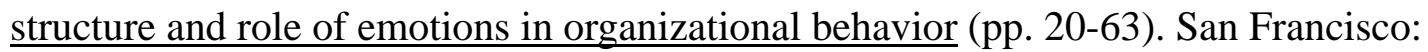
Jossey-Bass.

Weiss, H. M., \& Kurek, K. E. (2003). Dispositional influences on affective experiences at work. In M. R. Barrick \& A. M. Ryan Eds.), Personality and work: Reconsidering the role of personality in organizations (pp.121-149). USA: Jossey-Bass.

Whyte, G. (1986). Escalating commitment to a course of action: A reinterpretation. Academy of Management Review, 11, 311-321.

Whyte, G. (1993). Escalating commitment in individual and group decision making: A prospect theory approach. Organizational Behavior and Human Decision Processes, 54, 430-455.

Whyte, G., Saks, A. M., \& Hook, S. (1997). When success breeds failure: The role of self-efficacy in escalating commitment to a losing course of action. Journal of Organizational Behavior, 18, 415-432.

Wofford, J. C., Goodwin, V. L., \& Daly, P. S. (1999). Cognitive-affective stress propensity: A field study. Journal of Organizational Behavior, 20, 687-707.

Wong, K. F. E. (in press). The role of risk in making decision under escalation situations. Applied Psychology: An International Review.

Yik, M. S. M., \& Russell, J. A. (2004). On the relationship between circumplexes: Affect and Wiggins' IAS. Multivariate Behavioral Research, 39, 203-230.

Yik, M. S. M., Russell, J. A., Ahn, C.-K., Fernández Dols, J. M., \& Suzuki, N. (2002). Relating the Five-Factor Model of personality to a circumplex model of affect: A five language study. In R. R. McCrae \& J. Allik (Eds.), The Five-Factor Model of personality across cultures (pp. 79-104). New York: Kluwer Academic/Plenum Publishers.

Zeelenberg, M., \& Beattie, J. (1997). Consequences of regret aversion. 2. Additional evidence for effects of feedback on decision making. Organizational Behavior and Human Decision Processes, 72, 63-78. 


\section{Appendix A}

Candidate A’s Previous Sales and Earnings record

\begin{tabular}{ccc}
\hline Fiscal Year & Sales (in thousand of dollars) & Earnings (in thousand of dollars) \\
\hline 1986 & 624 & 14.42 \\
1987 & 626 & 10.27 \\
1988 & 649 & 8.65 \\
1989 & 681 & 8.46 \\
1990 & 674 & 4.19 \\
1991 & 702 & 5.35 \\
1992 & 717 & 3.92 \\
1993 & 741 & 4.66 \\
1994 & 765 & 2.48 \\
1995 & 770 & $\mathbf{- 0 . 1 2}$ \\
1996 & 769 & $\mathbf{- 0 . 6 3}$ \\
\hline
\end{tabular}

Candidate B’s Previous Sales and Earnings record

\begin{tabular}{ccc}
\hline Fiscal Year & Sales (in thousand of dollars) & Earnings (in thousand of dollars) \\
\hline 1986 & 670 & 15.31 \\
1987 & 663 & 10.92 \\
1988 & 689 & 11.06 \\
1989 & 711 & 10.44 \\
1990 & 724 & 9.04 \\
1991 & 735 & 6.38 \\
1992 & 748 & 5.42 \\
1993 & 756 & 3.09 \\
1994 & 784 & 3.26 \\
1995 & 788 & $\mathbf{- 0 . 8 1}$ \\
1996 & 791 & $\mathbf{- 0 . 8 0}$ \\
\hline
\end{tabular}

Contributions to Sales and Earnings of the selected candidate (Candidate A) after joining your team

\begin{tabular}{ccc}
\hline Fiscal Year & Sales (in thousand of dollars) & Earnings (in thousand of dollars) \\
\hline & After joining your team & \\
1997 & 771 & $\mathbf{- 1 . 1 2}$ \\
1998 & 774 & $\mathbf{- 1 . 9 6}$ \\
1999 & 762 & $-\mathbf{3 . 8 7}$ \\
2000 & 778 & $-\mathbf{3 . 8 3}$ \\
2001 & 783 & $\mathbf{- 4 . 1 6}$ \\
\hline
\end{tabular}




\section{Appendix B}

\section{Items of the performance measure}

1. How would you describe this candidate's performance in sales? Please circle your choice

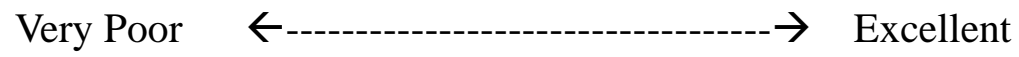

$\begin{array}{lllllll}1 & 2 & 3 & 4 & 5 & 6 & 7\end{array}$

2. How would you describe this candidate's performance in earnings? Please circle your choice Very Poor

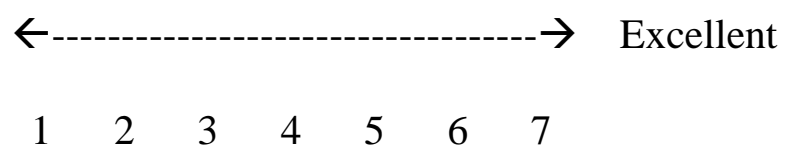

3. How would you describe this candidate's overall performance? Please circle your choice

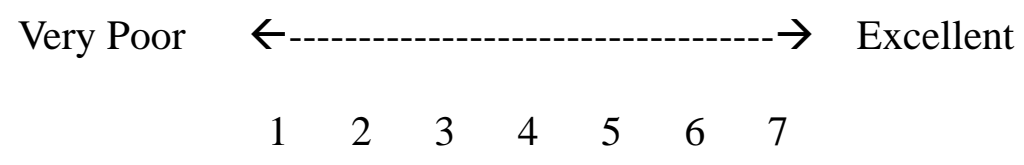

4. How would you describe this candidate's overall contribution to your team? Please circle your choice

Not at all

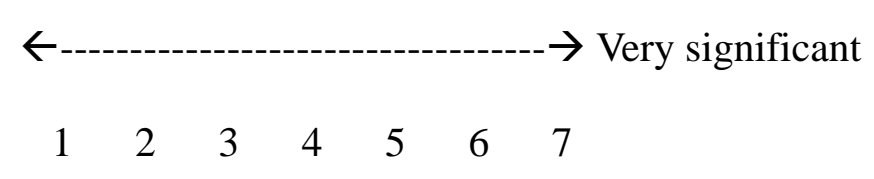




\section{Appendix C}

In Study 3, participants across both conditions read the same instructions about the two games and the scoring method. The instructions were as follows:

"There are two different games in the present experiment. You can select either one in Phase 1. One of the games is on visual judgment. You will see a series of white rectangles. Part of each rectangle is covered by a black patch. Your task is to estimate the percentage of area of the white rectangle covered by the black patch. Another game is on numerical judgment. You will answer a series of questions pertaining to numerical estimates in daily life (e.g., What is the mean temperature of City A in degrees Celsius?) Your task is to give an estimate as accurate as possible."

"You will be asked to select one of the games and play for 10 trials. Irrespective of your choice, you will earn certain points after each trial. You will win a jackpot of $\$ 50$ when you earn a total of 1000 points from the experiment.

The number of points you can earn on each trial will range from 1 (for a relatively inaccurate estimate) to 200 (for a relatively accurate estimate). Note that the number of points that you will earn will depend on the accuracy of your estimate in relation to those made by previous participants in this experiment. It is thus possible for you to earn only a few points with a pretty accurate judgment or a substantial number of points with a modestly accurate estimate." 


\section{Footnote}

1. The term neuroticism and negative affectivity are often used interchangeably in the literature (Brief \& Weiss, 2002; Watson, 2000). 
Table 1

Summary of the three theoretical perspectives with respect to the Negative Affect-Responsibility interaction on escalation of commitment

\begin{tabular}{|c|c|c|c|}
\hline & \multicolumn{3}{|c|}{ Perspectives } \\
\hline & Coping & Depressive realism & Cognitive dissonance \\
\hline $\begin{array}{l}\text { Locus at which negative } \\
\text { affect plays the role }\end{array}$ & Coping strategies & $\begin{array}{c}\text { Prospect } \\
\text { optimisticity and } \\
\text { decision quality }\end{array}$ & $\begin{array}{c}\text { Belief-behavior } \\
\text { discrepancy }\end{array}$ \\
\hline Dependence on responsibility & Yes & No & Yes \\
\hline $\begin{array}{l}\text { Prediction on the Negative } \\
\text { Affect-Responsibility } \\
\text { interaction }\end{array}$ & Figure 1 (left panel) & $\begin{array}{l}\text { Figure } 1 \text { (middle } \\
\text { panel) }\end{array}$ & Figure 1 (right panel) \\
\hline
\end{tabular}


Table 2

The means, standard deviations, and zero-order correlation of the variables measured in Study 1

\begin{tabular}{|c|c|c|c|c|c|c|c|c|}
\hline Variable & $\underline{\mathrm{M}}$ & SD & 1 & 2 & 3 & 4 & 5 & 6 \\
\hline 1. Probability of authorizing the next 1 & 59.29 & 25.79 & -- & & & & & \\
\hline \multicolumn{9}{|l|}{ million dollars $(0-100)$} \\
\hline 2. Neuroticism (1-7) & 3.81 & .99 & -.09 & -- & & & & \\
\hline 3. Responsibility $(0=$ non-responsible, $1=$ & .50 & .50 & $.13^{*}$ & .03 & -- & & & \\
\hline \multicolumn{9}{|l|}{ responsible) } \\
\hline 4. Age & 20.46 & 1.06 & .02 &.$-.13^{*}$ & -.11 & -- & & \\
\hline 5. Gender ( $0=$ female, $1=$ male $)$ & .49 & .50 & .02 & $-.31^{* *}$ & .01 & 10 & -- & \\
\hline 6. Knowledge in financial decision-making & 4.32 & 1.05 & .03 & $-.13^{*}$ & -.03 & .05 & .10 & -- \\
\hline$(1-7)$ & & & & & & & & \\
\hline
\end{tabular}

$* \mathrm{p}<.05$, two-tailed; ** $\mathrm{p}<.01$, two-tailed. 
Table 3

$\underline{\text { Results (standardized beta coefficients) of hierarchal multiple regression of Study } 1}$

Variable

Step 1

Control variables

Age

Gender $(0$ = female, 1 = male $)$

Knowledge in Financial decision-making

Study variables

Neuroticism

Responsibility ( 0 = non responsible, 1 = responsible)

Neuroticism $\times$ Responsibility

$\Delta \underline{\mathrm{R}}^{2}$

F change

Overall model $\underline{\mathrm{R}}^{2}$

Adjusted $\underline{R}^{2}$

Overall model $\underline{\mathrm{F}}$

$$
-.02
$$

$-.02$

.03

$-.01$

.00

$-.05$

$-.05$

.03

.03

Step 3

Overall

Step $2 \quad$ Step 3

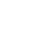


Table 4

The means, standard deviations, and zero-order correlation of the variables measured in Study 2

\begin{tabular}{|c|c|c|c|c|c|c|c|c|}
\hline Variable & $\underline{\mathrm{M}}$ & SD & 1 & 2 & 3 & 4 & 5 & 6 \\
\hline 1. Performance evaluation (1-7) & 3.62 & .92 & -- & & & & & \\
\hline 2. Neuroticism (1-7) & 4.03 & .93 & $-.18^{*}$ & -- & & & & \\
\hline 3. Responsibility ( 0 = non-responsible, $1=$ & .45 & .92 & $.16^{*}$ & -.01 & -- & & & \\
\hline \multicolumn{9}{|l|}{ responsible) } \\
\hline 4. Age & 19.50 & .63 & -.05 & -.09 & -.07 & -- & & \\
\hline 5. Gender ( 0 = female, $1=$ male $)$ & .27 & .44 & -.00 & $-.33 * *$ & -.02 & .11 & -- & \\
\hline
\end{tabular}

$* \mathrm{p}<.05$, two-tailed; ** $\mathrm{p}<.01$, two-tailed. 
Table 5

$\underline{\text { Results (standardized beta coefficients) of hierarchal multiple regression of Study } 2}$

\begin{tabular}{|c|c|c|c|}
\hline \multirow[t]{2}{*}{ Variable } & \multicolumn{3}{|c|}{ Overall } \\
\hline & Step 1 & Step 2 & Step 3 \\
\hline \multicolumn{4}{|l|}{ Control variables } \\
\hline Age & -.05 & -.05 & -.03 \\
\hline Gender ( 0 = female, 1 = male $)$ & .00 & -.06 & -.05 \\
\hline \multicolumn{4}{|l|}{ Study variables } \\
\hline Neuroticism & & $-.20 *$ & $-.21 *$ \\
\hline Responsibility ( 0 = non-responsible, $1=$ responsible) & & $.16^{*}$ & $.16^{*}$ \\
\hline Neuroticism $\times$ Responsibility & & & $-.24 * *$ \\
\hline$\Delta \underline{\mathrm{R}}^{2}$ & & .06 & .06 \\
\hline$\underline{F}$ change & & $5.54^{*}$ & $10.71 * *$ \\
\hline Overall model $\underline{\mathrm{R}}^{2}$ & .00 & .06 & .12 \\
\hline Adjusted $\underline{\mathrm{R}}^{2}$ & -.01 & .04 & .09 \\
\hline Overall model $\underline{F}$ & .22 & $2.88 *$ & $4.58 * *$ \\
\hline
\end{tabular}

Note: The dependent variable was the performance rating on the previously selected candidate.

$* \mathrm{p}<.05$, two-tailed; ** $\mathrm{p}<.01$, two-tailed. 
Table 6

The means, standard deviations, and zero-order correlation of the variables measured in Study 3

\begin{tabular}{|c|c|c|c|c|c|c|c|c|c|}
\hline Variable & $\underline{\mathrm{M}}$ & SD & 1 & 2 & 3 & 4 & 5 & 6 & 7 \\
\hline 1. Money spent on the same task (\$0-\$10) & 4.55 & 2.71 & -- & & & & & & \\
\hline 2. State negative affect (1-5) & 1.44 & .47 & .03 & -- & & & & & \\
\hline 3. Responsibility $(0=$ non-responsible, $1=$ & .5 & .5 & $.44^{*}$ & .18 & -- & & & & \\
\hline \multicolumn{10}{|l|}{ responsible) } \\
\hline 4. Self-efficacy (Visual judgment, 1-5) & 2.70 & .81 & .23 & -.15 & -.19 & -- & & & \\
\hline 5. Self-efficacy (Numerical judgment, 1-5) & 2.60 & .85 & -.16 & -.03 & -.09 & $.49 * *$ & -- & & \\
\hline 6. Age & 21.83 & 3.32 & -.17 & -.07 & -.15 & -.11 & -.25 & -- & \\
\hline 7. Gender ( 0 = female, 1 = male) & .5 & .5 & -.16 & .07 & -.10 & $.31^{*}$ & $.42^{* *}$ & -.22 & -- \\
\hline
\end{tabular}

$*<.05$, two-tailed; $* *<.01$, two-tailed. 
Table 7

$\underline{\text { Results (standardized beta coefficients) of hierarchal multiple regression of Study } 3}$

\begin{tabular}{|c|c|c|c|}
\hline \multirow[t]{2}{*}{ Variable } & \multicolumn{3}{|c|}{ Overall } \\
\hline & Step 1 & Step 2 & Step 3 \\
\hline \multicolumn{4}{|l|}{ Control variables } \\
\hline Age & -.21 & -.15 & -.11 \\
\hline Gender ( 0 = female, 1 = male) & .18 & .12 & .08 \\
\hline Self-efficacy (Visual judgment) & $.35^{*}$ & $.34^{*}$ & $.37^{*}$ \\
\hline Self-efficacy (Numerical Judgment) & -.30 & $-.31 \dagger$ & $-.41 *$ \\
\hline \multicolumn{4}{|l|}{ Study variables } \\
\hline Unpleasant Affect & & -.01 & -.14 \\
\hline Responsibility ( 0 = non responsible, $1=$ responsible) & & $.41 * *$ & $.30 \dagger$ \\
\hline Unpleasant Affect $\times$ Responsibility & & & $-.34^{*}$ \\
\hline$\Delta \underline{\mathrm{R}}^{2}$ & & .16 & .09 \\
\hline$\underline{F}$ change & & $3.98 *$ & $5.14^{*}$ \\
\hline Overall model $\underline{\mathrm{R}}^{2}$ & .19 & .35 & .44 \\
\hline Adjusted $\underline{\mathrm{R}}^{2}$ & .10 & .23 & .32 \\
\hline Overall model $\underline{\mathrm{F}}$ & 2.07 & $2.95^{*}$ & $3.57 * *$ \\
\hline
\end{tabular}

Note: The dependent variable was the amount of money spent on the same judgment task.

$\dagger \mathrm{p}<.1$, two-tailed; ${ }^{*} \mathrm{p}<.05$, two-tailed; $* * \mathrm{p}<.01$, two-tailed 


\section{Figure Captions}

Figure 1. Negative Affect-Escalation relationships as a function of personal responsibility derived from the coping (left panel), depressive realism (middle panel), and cognitive dissonance perspectives (right panel).

Figure 2. The Negative Affect-Escalation relationships as a function of personal responsibility revealed in Studies 1 to 3. 

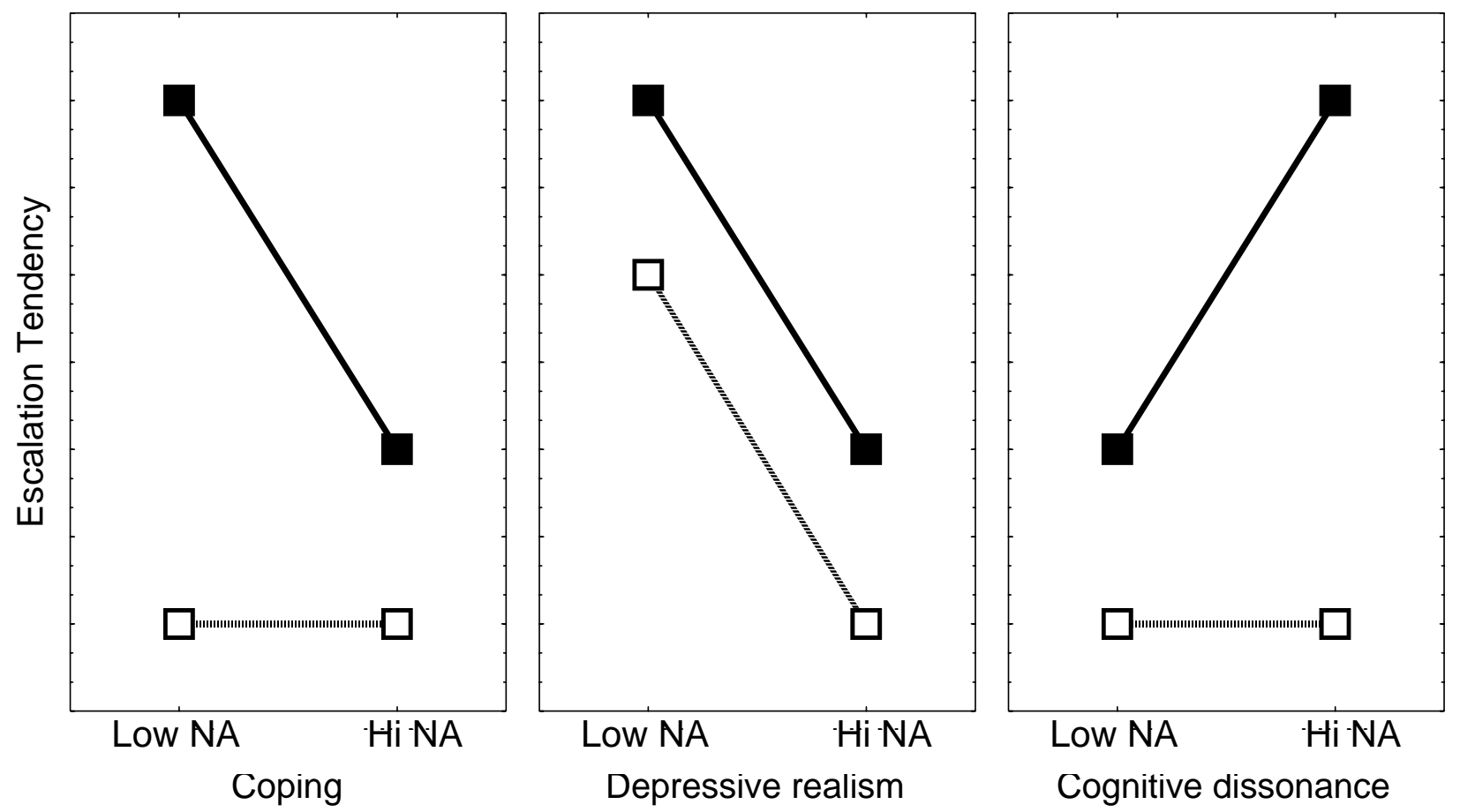

Note: NA = Negative Affect 


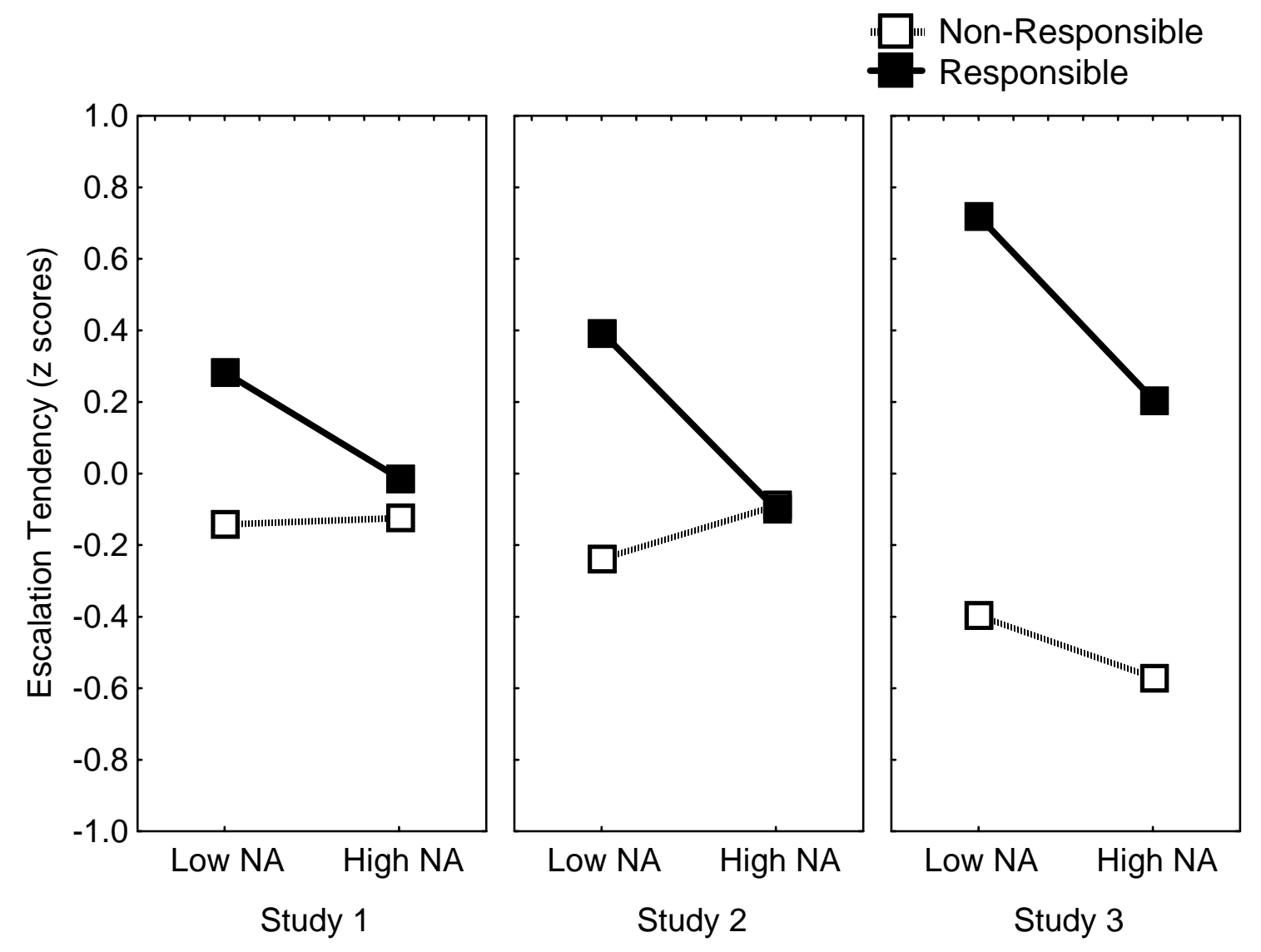

